\title{
The global age of the algorithm: Social credit, Xinjiang, and the financialisation of governance in China*
}

Nicholas Loubere and Stefan Brehm

Beautiful credit! The foundation of modern society. Who shall say that this is not the golden age of mutual trust, of unlimited reliance upon human promises?

- Mark Twain and Charles Dudley Warner, The Gilded Age: A Tale of Today (1873)

I

$\mathrm{n}$ recent years, few news items out of China have generated as much anxiety and fear in Western media and public discourse as the Chinese Government's ongoing attempts to create a 'social credit system' aimed at rating the trustworthiness of individuals and companies. Most major Western media outlets have spent significant energy warning about China's efforts to create an Orwellian dystopia. The most hyperbolic of these, The Economist, has even run with menacing headlines like 'China Invents the Digital Totalitarian State' and 'China's Digital Dictatorship' (The Economist 2016b, 2016c). These articles both implicitly and explicitly depict social credit as something unique to China-a nefarious and perverse digital innovation that could only be conceived of and carried out by a regime like the Chinese Communist Party (Daum 2017).

Social credit is thus seen as signalling the onset of a dystopian future that could only exist in the Chinese context. But how unique to China is this attempt to 'build an environment of trust', to quote the State Council, using new digital forms of data collection and analysis (General Office of the State Council 2016)? Is this Orwellian social credit system indicative of an inherently Chinese form of digital life, or is it a dark manifestation

"This essay was originally published in the Made in China Journal (vol. 3, no. I, 2018), doi.org/ / 0.22459/MIC.03.0 I.20 8 8.07. The article has been updated for inclusion in this volume. 
of our collective impulses to increase transparency and accountability (at the expense of privacy), and to integrate everyone into a single 'inclusive' system to more easily categorise, monitor, and standardise social activity? In this essay, we propose that the Chinese social credit system should not be exoticised or viewed in isolation. Rather, it must be understood as merely one manifestation of the global age of the algorithm-an age that is sadly coming to maturity through the ongoing experiments with digital social control in Xinjiang and elsewhere.

\section{Engineering a trustworthy society}

So, what is social credit, and how is it linked to emerging forms of algorithmic governance? While there have long been discussions about creating an economic and social rating system in China, they took a much more concrete form in 2014, with the publication of a high-level policy document outlining plans to create a nationwide social credit system by 2020 (State Council 2014). At the root of current Chinese social credit ambitions is the fact that China lacks the infrastructure to systematically assess and evaluate risk for both individuals and businesses, which adds to the economic costs of doing business, particularly in the financial sphere. As such, Chinese social credit should be understood, first and foremost, as an attempt to build a comprehensive economic risk-assessment system allowing for smoother economic integration.

Despite the goal of having an integrated, nationwide system by 2020 , social credit is still far from being unified or centralised. Like most new policies in China, social credit is being subjected to the country's distinctive policy modelling process (Heilmann 2008), in which local governments produce their own interpretations of policies and then vie to have them become national models. By 2019, approximately 28 localities had been labelled official 'demonstration cities' and were allowed to experiment and innovate within the limitations of the policy framework (Daum 2019). In contrast to other policies, however, eight large internet companies were also initially given licences to run their own pilot programs (Loubere 2017a). The most widely discussed private social credit system was Alibaba's Sesame Credit, which utilised opaque algorithms to arrive at social credit scores for its customers. Those with high scores have been able to access a range of benefits from other Alibaba businesses and their partners (Bislev 2017). However, while Sesame Credit is significant due to the huge amounts of economic data held by Alibaba through Alipay 
and Ant Financial, the Chinese Government ultimately cancelled its pilot status along with that of the other private companies, and these initiatives now 'essentially function like loyalty rewards programs' (Matsakis 2019).

\section{Financial(ised) inclusion}

While social credit can be seen as an outgrowth of our collective impulse to achieve a more trustworthy society, a unified fully functioning social credit system will ultimately turn the quest for trust through transparency and accountability upside down because it will hold citizens responsible vis-a-vis their rulers. At the core of the emerging system, the state and financial actors define, quantify, and calculate trustworthiness and honesty; it is a technocratic fix based on the logic that, with the correct set of algorithms, the good citizen or company can be engineered into society. Social credit therefore seeks to transform individuals into a new 'civilised' (and 'credit conscious') population through the imposition of a system of incentives and disincentives that can mould logical profit-maximising citizens into civilised subjects.

In the case of China's proposed social credit system - as with any credit rating system-these rewards and punishments are meted out through engagement with, and incorporation into, the market. The calculation of credit scores requires market activity, which in turn requires a credit score. Moreover, if social credit is to live up to its technocratic promise of systematically eliminating untrustworthiness, everyone must be assessed equally - that is, everyone must be included in the system. In the absence of a social credit score, the worst must be assumed, meaning that the burden of proving one's trustworthiness falls to the individual. Thus, in a society dominated by social credit, integration into the socioeconomic system is a necessity rather than a choice. In this way, China's social credit resonates with the global financial inclusion project, which seeks to integrate marginal and impoverished populations into the global capitalist system-primarily through expanded access to credit-as a means of promoting economic development and social empowerment.

In the same way that the Chinese social credit system appears poised to extract huge amounts of personal data from individuals in its quest to create a trustworthy society, proponents of financial inclusion justify intrusive methods of assessing creditworthiness to reduce lender risk from untrustworthy borrowers. Indeed, just months before its hyperbolic headlines about China's digital authoritarianism, The Economist praised 
the use of psychometrics and other personal digital data by lenders in developing contexts as being a beneficial financial innovation (The Economist 2016a). In this way, the financial inclusion project depicts the application of financialised logics as the means of producing a more fair and accountable inclusive system, where the trustworthy reap rewards they were denied in the past. However, underpinning this neoliberal fantasy is a glaring contradiction that shatters the illusion of inclusion as being unbiased and fair: those with capital can set the terms of their engagement with the capitalist system much more easily than those without.

This points to the fact that the rich will be able to extract more of the rewards from their participation in financialised rating systems-such as the social credit system - while largely avoiding the sanctions. Moreover, punishments are much more dramatic for those without accumulated capital, as their very existence depends on their continued participation in the capitalist system for daily survival. From this perspective, the spectre of China's financialised social credit system portends a society comprising individual micro-entrepreneurs operating in a shared economic mode in which livelihoods are determined by credit scores. Indeed, Sesame Credit already works with sharing-economy apps, such as Daowei, which provides a platform for a gig economy comprising individuals (with their credit scores listed) advertising the sale of their services or products (Loubere 2017b). Those looking for a plumber in the area can select one with the highest score, just as people in the West choose hotels and restaurants based on Yelp or TripAdvisor reviews.

\section{Financialisation gone wild}

In this sense, the emergence of social credit represents an unprecedented climax of the global financialisation project. Financialisation can be broadly defined as the increasing role of financial motives, financial markets, financial actors, and financial institutions in the operation of [the] domestic and international economy' (Epstein 2005: 3). Social credit opens the door to financialising social behaviour. To elaborate on this claim, consider the relationship between social and financial capital. The Organisation for Economic Co-operation and Development (OECD), for example, defines social capital as 'networks together with shared norms, values and understandings that facilitate co-operation within or among groups' (Keeley 2007: 103). In the digital age, these networks become 
the linchpins between the social and the economic spheres. On the one hand, networks are more concrete and easier to observe than the norms and values shaping the perceptions and behaviour of network members. On the other hand, social networks represent a crucial means for both gaining access to material resources and shaping the rules for resource distribution. Thus, analysing and contextualising social networks in a big-data-driven world allows inferences to be made about both the social and the economic attributes of an individual.

Social credit establishes an explicit and tangible link between social behaviour and economic benefits. In this context, the state can assume a new role not dissimilar to that of a corporate shareholder. Social credit creates a market for social capital and transplants the rationale of profit maximisation into the realm of interpersonal relationships. Through managing networks, digital activity, and private action, an individual or organisation can impact social value and, by extension, financial capital. Thus, social credit creates new incentives that can be used to align the interests of citizens and organisations with those of the government. The state, as a shareholder in 'the people', enjoys the dividends of good behaviour and loyalty, which are rewarded through economic privileges. In this all-encompassing financialised system, social action becomes increasingly entrenched within the economic realm, and individual behaviour is shaped more and more by financial motives. In a nutshell, social credit represents the ultimate marketisation of political control because it provides incentives for maximising citizen value through politically and commercially aligned social behaviour.

Using algorithms to render citizens and organisations compliant with the visions and rationales of the ruling regime reduces the state's information and monitoring costs dramatically. In the context of China, this has the potential to reshape the 'fragmented authoritarian' model, which is characterised by decentralised decision-making and policy implementation (Mertha 2009). One could envision a future in which the many local officials and bureaucrats who enjoy privileges due to the central leadership's reliance on their support to govern the masses will be subject to the rule of algorithms themselves. Only a small elite would be needed to manage algorithmic rule, entailing a dramatic reconcentration of power. If Chinese experiments are successful, they will certainly serve as a model for many other countries: authoritarian regimes, democratic 
systems with authoritarian tendencies, and eventually democracies that struggle to maintain legitimacy in an increasingly polarised and fragmented political landscape.

\section{The repressive logics of financialised governance}

As noted above, despite the discourse of inclusion resulting in transparency and fairer distribution of resources, social credit and the financialisation of social behaviour are inherently biased and paradoxically result in socioeconomic exclusion within an all-encompassing inclusive system. In addition to being partial to those with capital, social credit will likely also widen other socioeconomic cleavages. Tests and experiments again and again confirm that data and algorithms are just as biased as society is and inevitably reproduce real-life segmentation and inequality (Bodkin 2017). Cathy O'Neil, the author of Weapons of Math Destruction, for instance, warns that we need algorithmic audits (O’Neil 2016). After all, algorithms are not some naturally occurring phenomena, but are the reflections of the people (and societies) that create them. For this reason, the rule of algorithms must not be mistaken as an upgraded, more rational, and hyper-scientific rule of law 2.0. This is particularly true in China, where the concept of the rule of law has been increasingly developed and theorised by the Party-State to justify its attempts to consolidate control over society (Rosenzweig et al. 2017).

In recent years, China has already been providing glimpses of the repressive possibilities of algorithmic rule. In particular, the ongoing construction of a sophisticated high-tech surveillance state in the Xinjiang Uyghur Autonomous Region anticipates a near future in which a digital social credit system sits at the core of a coercive security apparatus that is inherently biased against certain segments of society-producing dramatically inequitable and ultimately violent results (HRW 2018). The Xinjiang surveillance state includes police checkpoints, iris scans, mandatory spyware installed on mobile devices, and pervasive closed-circuit television (CCTV) with facial recognition software. These surveillance technologies feed into, and draw on, a large police database developed by the private defence company Landasoft that includes information about personal identity, family and friends, movement, shopping behaviour, and even DNA that is collected at medical check-ups organised by the government (Grauer 2021). Ultimately, these data are run through algorithms that assign residents with public safety scores deeming them 
'safe,' 'unsafe', or somewhere in between (Millward 2018). Those who are deemed to be a threat are often detained and sent to reeducation centres (Foreign Policy 2018). While this is not the government's proposed social credit system per se-as these types of data are not legally allowed to be collected for public or market information (Daum 2018) - the logic underpinning this type of coercive surveillance infrastructure and the dreams of a nationwide citizen rating system is largely the same.

These developments represent a new reality that, while shocking initially, has become a banal part of everyday existence in a few short years. It is becoming increasingly clear that Xinjiang is a testing ground for technologies and techniques that will soon be rolled out nationwide - and even beyond. China's massive surveillance market is also a global affair, with companies from around the world lining up to develop products for both the Chinese state and private businesses operating in the country (Strumpf and Wenxin 2017). This points to the fact that China is not developing its surveillance capabilities in isolation but is at the forefront of a global push towards increasingly centralised and interconnected surveillance apparatuses. Ratings systems like the proposed social credit system will inevitably sit at the centre of surveillance regimes, providing the basis for how individuals and organisations are monitored and assessed, and what they are able (and not able) to do within society.

\section{Our dark digital futures}

China's proposed social credit system and the ongoing construction of a surveillance state in Xinjiang represent the vanguard of more efficient means of socioeconomic control that are being taken up around the globe. They are dark outgrowths of the digital revolution's supposed 'liberation technologies'- underpinned by our very human compulsions for transparency, security, and fairness. Credit systems are, of course, not new, nor are they Chinese in origin. Most industrialised nations have been relying on credit ratings for a long time to quantify the financial risk of countries, firms, and individuals (Yu et al. 2015). Indeed, some of the most disturbing aspects of Chinese social credit, such as its integration into social media, are not uniquely or originally Chinese. In the United States, Affirm, a San Francisco-based lender headed by PayPal co-founder Max Levchin, has been experimenting with social media data to evaluate the credit risk of car buyers since 2013. And Lenddo, a Hong Kong-based company, took an even bolder approach and informed debtors' friends on 
Facebook when they did not pay instalments on time. Even the Orwellian nightmare unfolding in Xinjiang has its parallels elsewhere, such as with the recent revelations that in the United States, the New Orleans Police Department and the federal Immigration and Customs Enforcement (ICE) have been working with Peter Thiel's company Palantir Technologies (which also has connections with the Central Intelligence Agency and the Pentagon) to experiment with 'predictive policing' based on data collected from police databases, social media, and elsewhere (Fang 2018; Winston 2018; Hvistendahl 2021). Taken together, these developments reveal a vision of a digital future in which we are all locked in a continuous and banal system of monitoring, accounting, categorising, and tracking-which has potentially far-reaching consequences for those who challenge the hegemony in any way, or even just those who do not have the resources or capacity to participate in the socioeconomic system on the terms mandated.

Big-data-driven social benchmarking sparks entrepreneurs' and politicians' imaginations about the opportunities lying ahead. And even though not all visions will be economically or politically viable in all places in the world, the general trend appears to be global and irreversible. Social credit and the dreams of financialised governance are not Chinese or authoritarian particularities, but are, perhaps, our 'shared destiny' (共 同命运)—to use a term employed by President Xi Jinping when talking about the Chinese vision for the future of humanity (Barmé et al. 2014). This, however, makes it not less, but rather more, worrisome. The logical conclusion of society-wide financialisation is the blurring of the border between the political, social, and commercial realms, and the sharpening of the repressive tools wielded by the rich and powerful. In China, this scenario appears to be inevitable. To quote Lucy Peng, the chief executive of Ant Financial, Sesame Credit 'will ensure that the bad people in society don't have a place to go, while good people can move freely and without obstruction' (Hvistendahl 2017). 
This text is taken from Xinjiang Year Zero, edited by Darren Byler, Ivan Franceschini and Nicholas Loubere, published 2022, The Australian National University, Canberra, Australia.

doi.org/10.22459/XYZ.2021.13 